PATTERNS OF FAMILY MIGRATION: TWO METHODOLOGICAL APPROACHES

Luis J. Castro and Andrei Rogers

International Institute for Applied Systems Analysis, Laxenburg, Austria

RR-83-8

March 1983

Reprinted from Environment and Planning $A$, volume 15 number 2 (1983)

INTERNATIONAL INSTITUTE FOR APPLIED SYSTEMS ANALYSIS

Laxenburg, Austria 
Research Reports, which record research conducted at IIASA, are independently reviewed before publication. However, the views and opinions they express are not necessarily those of the Institute or the National Member Organizations that support it.

Reprinted with permission from Environment and Planning A 15(2):237-254.

Copyright (c) 1983 Pion Limited.

All rights reserved. No part of this publication may be reproduced or transmitted in any form or by any means, electronic or mechanical, including photocopy, recording, or any information storage or retrieval system, without permission in writing from the copyright holder. 


\section{FOREWORD}

The study of the evolution of human populations over time and space has been a major research activity at IIASA during the past several years. Central to this effort has been a focus on internal migration patterns. This article is part of that research agenda. It shows how family relationships among migrants are reflected in their age compositions. By disaggregating migrants into dependent and independent categories, the article illuminates the ways in which the age profiles of migrating populations are sensitive to relative changes in dependency levels.

A number of related publications on age profiles of migration are listed at the back of this reprint.

ANDREI ROGERS

Leader

Population Program 



\title{
Patterns of family migration: two methodological approaches
}

\author{
L J Castro, A Rogers \\ International Institute for Applied Systems Analysis, A-2361 Laxenburg, Austria \\ Received 15 December 1981
}

\begin{abstract}
It is widely recognized that many internal migrations are undertaken by individuals whose moves are dependent on those of others. For example, children migrate with their parents and wives with their husbands. This paper suggests two formulations of family migration that permit the introduction of such family dependencies into the population projection process.
\end{abstract}

The formal demography of migration and redistribution views interregional population transfers as a collection of independent individual movements. Yet it is widely recognized that many internal migrations are undertaken by individuals whose moves are dependent on those of others, for example, children migrating with their parents, wives with their husbands, grandparents with their children:

"The primary demographic events are the procreation of a new member of the population, the transition of a member from one population to another, and the death of a member. Despite prevalent practice, it is not self-evident that the individual is the appropriate unit for the study of such events. The procreating entity is the couple rather than the individual. From a sociological perspective, the only unit in society permitted (and obligated) to increase population size by procreation is the family. Likewise, as Josianne Duchene reminded us, the unit of migration is the family rather than the individual. (One working definition for family membership would be that the family consists of those who would migrate together)" (Ryder, 1978, page 219).

Because the formal demography of the family is still in its infancy, the focus on independent individual migrations is perhaps understandable. Nonetheless, it seems that future developments in the analysis and projection of multiregional population systems will need to introduce, however imperfectly, the perspective of family demography into the population projection process. This paper draws on the notion of model migration schedules (Rogers and Castro, 1981; Castro and Rogers, 1981) and of a household composition matrix (Akkerman, 1980) to introduce such a perspective in the modeling of migration patterns and their family dependency relationships.

Following the general practice of the United Nations (UN, 1973), we use the term 'family' to designate a group of individuals that are related by blood, adoption, or marriage, that live in the same dwelling, and that engage in 'joint' decisionmaking with respect to consumption and production (Kuznets, 1978).

\section{Dependency relationships}

The average size of family has fallen in every modernized industrial nation as a result of fertility and mortality declines:

"The fall in fertility has decreased the number of very large units; the fall in mortality has increased the proportion of small units by increasing the length of time couples survive after their children are grown" (Kobrin, 1976, page 127). Inasmuch as many, if not most, migrants are dependents traveling with the family head (Long, 1974), the importance of introducing the family as the basic unit in decompositions of migration schedules by family status is self-evident. 
Figure 1 illustrates the age composition, by sex, of the family population, $C(x)$, and family migrants, $N(x)$, contained in a $1 \%$ sample of the 1970 Mexican Census of Population (FSO, 1970) ${ }^{(1)}$. The age composition of the population exhibits the usual profile of relatively young populations experiencing high rates of natural increase.

The age profile of the migrants shows an unusually large share of infants and children in the total migrant population.

To analyze the impacts of high dependency levels, we begin by expressing the age profiles in figure 1 as weighted sums of the age compositions of family heads and of their dependents.

Let $K_{\mathrm{H}}(x)$ and $K_{\mathrm{D}}(x)$ denote, respectively, the number of family heads and dependents at age $x$ in the population, and let $O_{\mathrm{H}}(x)$ and $O_{\mathrm{D}}(x)$ denote the corresponding variables for migrants. Summing these over all ages $x$ gives the totals $K_{\mathrm{H}}(\cdot),{ }^{\prime} K_{\mathrm{D}}(\cdot), O_{\mathrm{H}}(\cdot)$, and $O_{\mathrm{D}}(\cdot)$, respectively; adding the numbers of heads and dependents gives
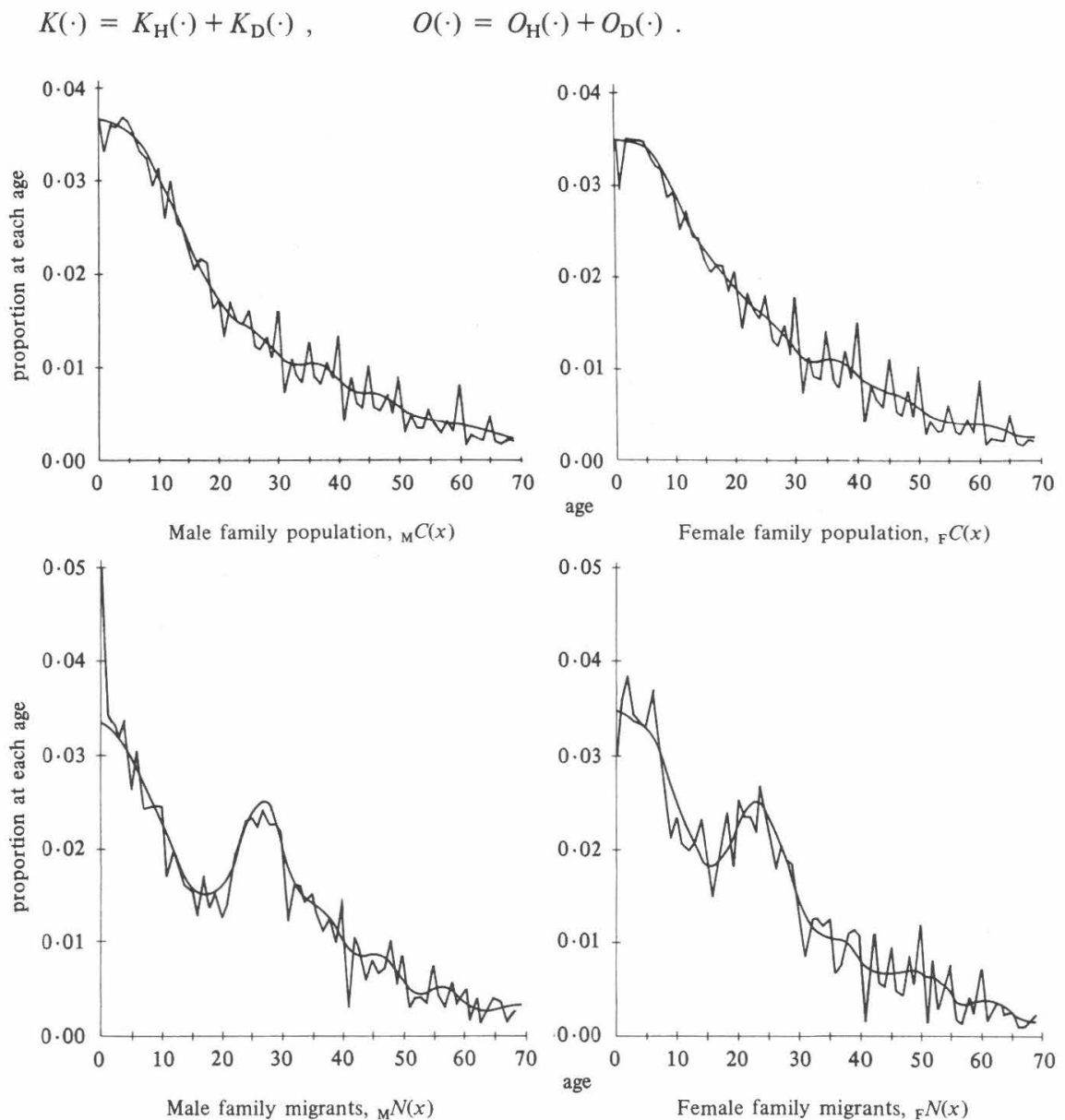

Figure 1. Age-specific family population $C(x)$, and family migration, $N(x)$, distribution, by sex, observed and smoothed: Mexico, 1970.

(1) The smooth line in each profile describes a cubic-spline interpolation of the raw data (described by the jagged line). The raw data were classified by single years of age. 
By definition

$$
\begin{aligned}
C(x) & =\frac{K(x)}{K(\cdot)}=\frac{K_{\mathrm{H}}(x)}{K(\cdot)}+\frac{K_{\mathrm{D}}(x)}{K(\cdot)} \\
& =\frac{K_{\mathrm{H}}(\cdot)}{K(\cdot)} \frac{K_{\mathrm{H}}(x)}{K_{\mathrm{H}}(\cdot)}+\frac{K_{\mathrm{D}}(\cdot)}{K(\cdot)} \frac{K_{\mathrm{D}}(x)}{K_{\mathrm{D}}(\cdot)} \\
& =k_{\mathrm{H}} C_{\mathrm{H}}(x)+k_{\mathrm{D}} C_{\mathrm{D}}(x),
\end{aligned}
$$

where $C(x)$ is the proportion of the population at age $x, C_{\mathrm{H}}(x)$ and $C_{\mathrm{D}}(x)$ are, respectively, the corresponding proportions among family heads and their dependents, and $k_{\mathrm{H}}$ is the fraction of the total population represented by family heads $\left(k_{\mathbf{D}}=1-k_{\mathrm{H}}\right)$. Analogously,

$$
N(x)=o_{\mathrm{H}} N_{\mathrm{H}}(x)+o_{\mathrm{D}} N_{\mathrm{D}}(x),
$$

where $N(x)$ is the proportion of migrants at age $x, N_{\mathrm{H}}(x)$ and $N_{\mathrm{D}}(x)$ are, respectively, the corresponding proportions among migrants of family heads and their dependents, and $o_{\mathrm{H}}$ is the fraction of the migrant population represented by family heads $\left(o_{\mathrm{D}}=1-o_{\mathrm{H}}\right)$.

Table 1 sets out the values obtained for the four fundamental ratios in the Mexican census data. We shall refer to $k_{\mathrm{H}}$ and $o_{\mathrm{H}}$ as head/population and head/migrant ratios, respectively, and to $k_{\mathrm{D}}$ and $o_{\mathrm{D}}$ as dependent/population and dependent $/$ migrant ratios, respectively. Figure 2 presents the associated four age profiles: $C_{\mathrm{H}}(x), C_{\mathrm{D}}(x)$, $N_{\mathrm{H}}(x)$, and $N_{\mathrm{D}}(x)$. These underlie the curves in figure 1 , which may be viewed as having been generated by weighted combinations of the profiles in figure 2 , the weights being the ratios set out in table 1 .

Two important observations regarding the headship and dependency characteristics of male and female populations and migrants are suggested by table 1. First, it is apparent that the ratios differ markedly according to sex: females exhibit lower headship ratios and larger dependency ratios. The male values for $k_{\mathrm{H}}$ and $o_{\mathrm{H}}$ are, respectively, 5.5 and 4.7 times larger than the corresponding ratios for females, whereas for males $k_{\mathrm{D}}$ and $o_{\mathrm{D}}$ are, respectively, only 0.72 and 0.59 times the level of those for females. Second, the relative prevalence of heads among migrants is greater than among the population as a whole. For each sex, the headship ratio of the

\begin{tabular}{|c|c|c|c|}
\hline Ratio & Value & atio & \\
\hline & males & females & males/females \\
\hline & Popula & & \\
\hline$k_{\mathrm{H}}$ & 0.325 & 0.059 & $5 \cdot 508$ \\
\hline$k_{\mathrm{D}}$ & 0.675 & 0.941 & 0.717 \\
\hline Total & 1.000 & $1 \cdot 000$ & \\
\hline & Migran & & \\
\hline$o_{\mathbf{H}}$ & 0.471 & $0 \cdot 100$ & $4 \cdot 710$ \\
\hline$O_{\mathrm{D}}$ & 0.529 & 0.900 & 0.588 \\
\hline Total & 1.000 & $1 \cdot 000$ & \\
\hline & Migran & opulation & \\
\hline$o_{\mathrm{H}} / k_{\mathrm{H}}$ & 1.449 & 1.695 & \\
\hline$o_{\mathrm{D}} / k_{\mathrm{D}}$ & 0.784 & 0.956 & \\
\hline
\end{tabular}
former is about $50 \%$ higher than the headship ratio of the latter.

Table 1. Head and dependency ratios for family population and family migrants, by sex: Mexico, 1970. 
Additional observations are motivated by the age profiles presented in figure 2, which illustrate the observed (cubic-spline-interpolated) population and migrant age compositions for heads and for dependents, disaggregated by sex. Although the male age profiles both for population and for migrants look rather similar ${ }^{(2)}$, those for females show systematic differences. For example, dependent female migrants exhibit a small peak near age 20 , whereas the corresponding dependent population does not. The importance of marriage as a reason for migrating may account for this difference. And the age profile of head female migrants appears to be bimodal whereas that of heads in the population in general does not. This possibly is a reflection of the fact that most migrating female heads are either young singles or middle-aged widows and divorcees. Finally, the male age profiles of dependents are steeper than those of females. This is probably a consequence of the earlier age at which male youths leave the family home in developing societies such as Mexico.
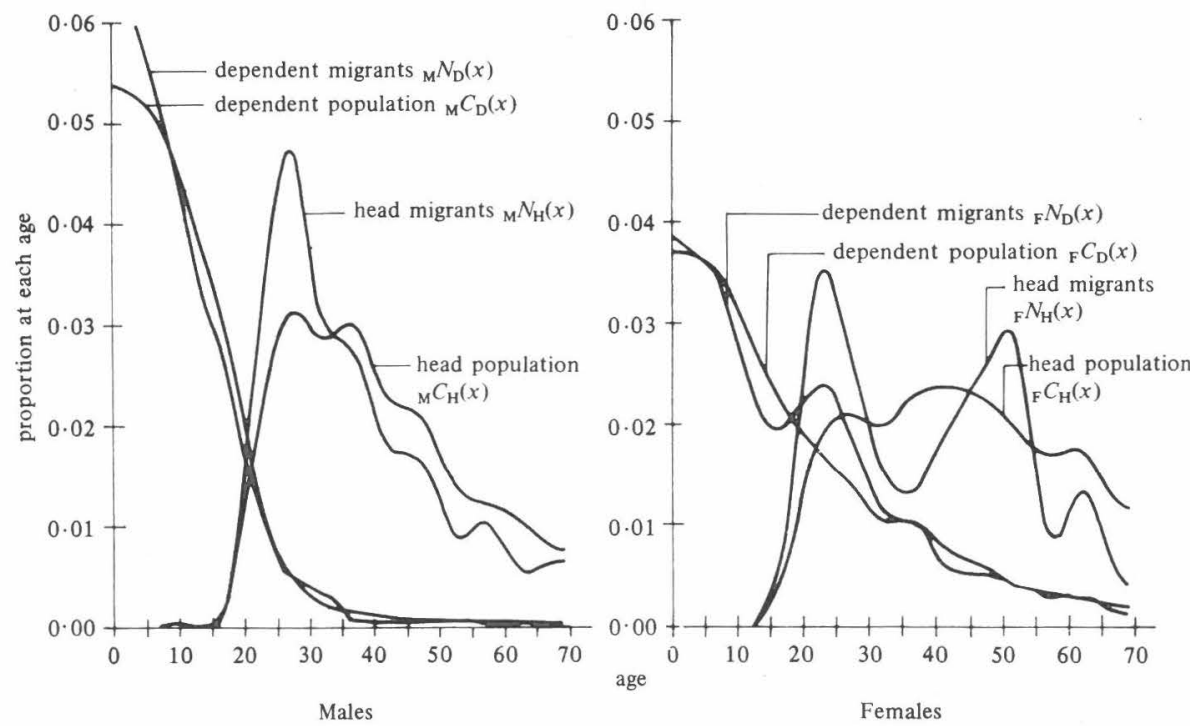

Figure 2. Age-specific population and migration compositions of heads and dependents, by sex: Mexico, 1970.

2 Model migration proportion schedules

To understand the influences that family composition and dependency relationships have on the age profiles of migrating individuals, it is useful to describe such profiles mathematically and then examine how their shapes respond to fundamental changes in dependency patterns.

The observed male and female migration proportion schedules in figure 1 appear to have the same fundamental profile as the model migration rate schedule defined in Rogers and Castro (1981):

$$
N(x)=N_{1}(x)+N_{2}(x)+c,
$$

where

$$
N_{1}(x)=a_{1} \exp \left(-\alpha_{1} x\right)
$$

(2) Except for the moderately heavier concentration of younger heads among migrants than in the population at large. 
for the pre-labor force component, and

$$
N_{2}(x)=a_{2} \exp \left\{-\alpha_{2}\left(x-\mu_{2}\right)-\exp \left[-\lambda_{2}\left(x-\mu_{2}\right)\right]\right\},
$$

for the labor force component, and $c$ is the constant term that improves the fit when migration at older ages is relatively high.

An alternative way of expressing equation (3) (Castro and Rogers, 1981) is a weighted linear combination of the density functions representing the three components:

$$
N(x)=\phi_{1} f_{1}(x)+\phi_{2} f_{2}(x)+\phi_{\mathrm{c}}\left(\frac{1}{w}\right),
$$

where

$w \quad$ is the last age included in the schedule,

$\phi_{1}, \phi_{2}$ are the relative shares of the pre-labor force and labor force components, respectively,

$\phi_{c} \quad$ is the share of the constant term, and

$f_{1}(x), f_{2}(x)$ are, respectively, the single and double exponential density functions given by

$$
\begin{aligned}
& f_{1}(x)=\alpha_{1} \exp \left(-\alpha_{1} x\right), \\
& f_{2}(x)=\frac{\lambda_{2}}{\Gamma\left(\alpha_{2} / \lambda_{2}\right)} \exp \left\{\left(-\alpha_{2}\right)\left(x-\mu_{2}\right)-\exp \left[-\lambda_{2}\left(x-\mu_{2}\right)\right]\right\} .
\end{aligned}
$$

Notice that $\phi_{1}+\phi_{2}+\phi_{\mathrm{c}}=1$ by definition.

Equations (3) through (8) imply that

$$
\begin{aligned}
& N_{1}(x)=\phi_{1} f_{1}(x), \\
& N_{2}(x)=\phi_{2} f_{2}(x),
\end{aligned}
$$

and

$$
c=\frac{\phi_{\mathrm{c}}}{w} \text {. }
$$

Equations (3), (9), (10), and (11) together provide a compact mathematical description of the age composition of migrating populations. In particular, the ratio of $\phi_{1}$ to $\phi_{2}$ defines a fundamental dependency relationship that will be examined next.

\section{Dependency relationships once again: a single-sex analysis}

The differences between male and female age profiles of heads and dependents, illustrated in figure 2, virtually disappear in a single-sex formulation. If migrating women are viewed as heads and their female children as dependents, then the proportions at each age for female heads and dependents assume similar profiles as those for males. In such instances, the model migration proportion schedule defined by equation (3) becomes a suitable description of the several age patterns, and the ratio $D_{0}, D_{0}=\phi_{1} / \phi_{2}$, assumes a central role as an indicator of dependency structure. It defines the number of dependents per labor force migrant and appears to be a close approximation of average family size among migrants. We shall call it the child-adult dependency migration ratio.

The child-adult dependency migration ratio varies as a function of the parameters of the model migration proportion schedule. If the constant term $c$ is close enough to zero to be ignored, then $\phi_{\mathrm{c}}=0$, and equations (4) through (9) imply that

$$
a_{1}=\phi_{1} \alpha_{1} \text {, }
$$


and

$$
a_{2}=\frac{\phi_{2} \lambda_{2}}{\Gamma\left(\alpha_{2} / \lambda_{2}\right)},
$$

where $\Gamma\left(\alpha_{2} / \lambda_{2}\right)$ is the gamma function value of $\alpha_{2} / \lambda_{2}$. Simple arithmetic then reveals that

$$
D_{o}=\frac{\phi_{1}}{\phi_{2}}=\frac{a_{1} \lambda_{2}}{a_{2} \alpha_{1} \Gamma\left(\alpha_{2} / \lambda_{2}\right)}
$$

The child-adult dependency migration ratio increases in value with $a_{1}$ and decreases with increases in $a_{2}, \alpha_{1}$, and the degree of asymmetry in the labor force component of the model schedule ${ }^{(3)}$.

Table 2 presents the parameters defining observed model migration proportion schedules for the Mexican profiles shown in figure 1, together with the child-adult dependency ratio. The same table gives for comparative purposes the corresponding values for the national profiles of Mexico, Sweden, USA, and USSR, and for two regional profiles in Sweden. Figure 3 contrasts the dependency characteristics of the former profiles by sex, country, and region.

Is the child-dependency ratio among migrants lower than for the population as a whole? To answer this question, one needs only to replace $N(x)$ by $C(x)$ and set $\phi_{\mathrm{c}}=0$ in the argument starting with equation (3). The $N(x)$ and $C(x)$ schedules may be composed by weighting differently the same dependent and head density functions, that is, the same single and double exponential curves. Hence in what follows, we shall assume that $N_{1}(x)$ and $N_{2}(x)$ are described by the same density functions as are $C_{1}(x)$ and $C_{2}(x)$, respectively. Thus

$$
\begin{aligned}
& N(x)=\phi_{1 \mathrm{~N}} f_{1}(x)+\phi_{2 \mathrm{~N}} f_{2}(x), \\
& C(x)=\phi_{1 \mathrm{C}} f_{1}(x)+\phi_{2 \mathrm{C}} f_{2}(x),
\end{aligned}
$$

where $\phi_{1}$ and $\phi_{2}$ now receive an additional subscript to distinguish age compositions of migrants from those of the population as a whole, and $D_{\mathrm{C}}=\phi_{1 \mathrm{C}} / \phi_{2 \mathrm{C}}$ defines the child-adult dependency population ratio.

This child-dependency ratio is defined by the ratio of the weights associated with

\begin{tabular}{|c|c|c|c|c|c|c|c|c|}
\hline \multirow{3}{*}{$\begin{array}{l}\text { Parameters } \\
\text { and } \\
\text { dependency } \\
\text { ratio }\end{array}$} & \multicolumn{6}{|c|}{ National profiles } & \multicolumn{2}{|c|}{$\begin{array}{l}\text { Regional profiles, } \\
\text { Sweden }^{\text {a }}\end{array}$} \\
\hline & \multicolumn{3}{|l|}{ Mexico } & \multirow{2}{*}{$\begin{array}{l}\text { Sweden } \\
\text { total }\end{array}$} & \multirow{2}{*}{$\begin{array}{l}\text { USA } \\
\text { total }\end{array}$} & \multirow{2}{*}{$\begin{array}{l}\text { USSR } \\
\text { total }\end{array}$} & \multirow{2}{*}{$\begin{array}{l}\text { NMR } \\
\text { females }\end{array}$} & \multirow{2}{*}{$\begin{array}{l}\text { UNR } \\
\text { females }\end{array}$} \\
\hline & males & females & total & & & & & \\
\hline$a_{1}$ & $0 \cdot 040$ & 0.037 & 0.038 & 0.027 & 0.026 & 0.007 & 0.017 & 0.019 \\
\hline$\alpha_{1}$ & 0.088 & 0.061 & 0.074 & 0.081 & 0.036 & 0.022 & 0.030 & 0.097 \\
\hline$a_{2}$ & 0.035 & 0.029 & $0 \cdot 031$ & $0 \cdot 054$ & 0.042 & 0.133 & $0 \cdot 110$ & 0.098 \\
\hline$\mu_{2}$ & $25 \cdot 11$ & $22 \cdot 55$ & $25 \cdot 10$ & $18 \cdot 76$ & $15 \cdot 08$ & $17 \cdot 72$ & $19 \cdot 31$ & $17 \cdot 53$ \\
\hline$\alpha_{2}$ & $0 \cdot 158$ & $0 \cdot 214$ & 0.175 & 0.073 & $0 \cdot 121$ & 0.159 & 0.208 & $0 \cdot 141$ \\
\hline$\lambda_{2}$ & $0 \cdot 273$ & $0 \cdot 260$ & 0.204 & 0.483 & 0.573 & 0.375 & 0.440 & 0.733 \\
\hline$c$ & 0.006 & 0.005 & 0.005 & $0 \cdot 000$ & $0 \cdot 000$ & 0.000 & 0.000 & 0.002 \\
\hline$D_{o}$ & $2 \cdot 277$ & $4 \cdot 800$ & 3.020 & 0.491 & $2 \cdot 310$ & 0.433 & $1 \cdot 210$ & 0.306 \\
\hline
\end{tabular}
the age profiles of dependents and heads, the single and the double exponential

Table 2. Parameters defining observed model migration proportion schedules: national profiles of Mexico, 1970; Sweden, 1974; USA, 1970; USSR, 1974; and two regional profiles in Sweden, 1974.

a NMR-north middle region; UNR-upper north region.

(3) The index of labor force asymmetry is defined as $\lambda_{2} / \alpha_{2}$ by Rogers and Castro (1981). 
distributions, respectively. In the single-sex formulation, dependents are simply individuals who have not left home to become heads. To examine analytically some of the underlying patterns of 'head formation', let $y_{0}$ denote the age at which an appreciable number of individuals first leave home to establish their own household. Since marriage is an important reason for leaving the family home, it is likely that the density function describing the pattern of head formation by age is similar to the one used in nuptiality studies, that is, the double exponential function. If $g(y)$ is such a function then

$$
G(x)=\int_{y_{0}}^{x} g(y) \mathrm{d} y
$$

defines the proportion of individuals who have ever left home by age $x$, that is, who are heads.

How is $G(x)$ related to $f_{1}(x)$ and $f_{2}(x)$ ? Since $f_{2}(x)$ defines the proportion of the population of heads that are of age $x$ and $G(x)$ defines the proportion of the population who are heads by age $x$, it is evident that in a stable population growing at an intrinsic rate of growth $r$,

$$
f_{2}(x)=\frac{\exp (-r x) l(x) G(x)}{\int_{0}^{\infty} \exp (-r y) l(y) G(y) \mathrm{d} y},
$$

where $l(x)$ denotes the probability of surviving from birth to age $x$. For similar

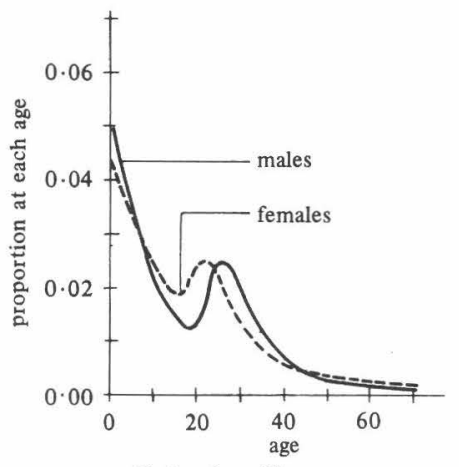

National profiles of Mexico by sex

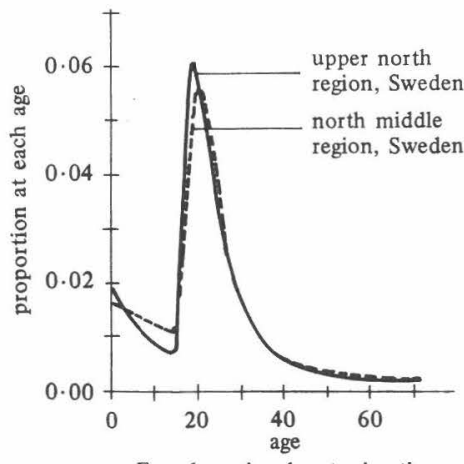

Female regional out-migration flows of Sweden (two regions)

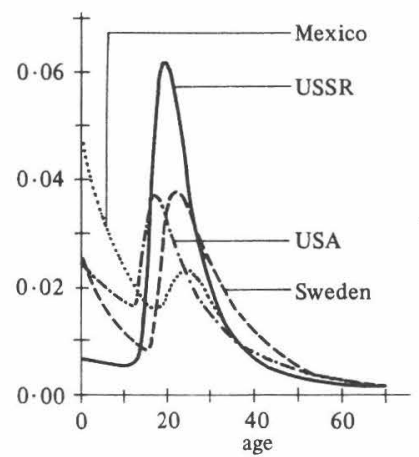

Total (males and females) national profiles for different countries

Figure 3. Observed model migration proportion profiles by sex, countries, and regions. 
reasons,

$$
f_{1}(x)=\frac{\exp (-r x) l(x)[1-G(x)]}{\int_{0}^{\infty} \exp (-r \dot{y}) l(y)[1-G(y)] \mathrm{d} y} .
$$

Figure 4 illustrates the above argument with hypothetical data. First, figure 4(a) presents the survivorship curve $l(x)$, which is that of the Brass standard with $\alpha=-0.8$ and $\beta=1.75$ with an expectation of life at birth of approximately sixtynine years (Brass, 1971); and the head formation curve $G(x)$ is the Coale-McNeil double exponential (Coale and McNeil, 1972) expressed by the Rodriguez and Trussell standard (Rodriguez and Trussell, 1980) with a mean and variance of age of becoming head of 22 and 5 years, respectively. Figure 4(b) shows the resulting dependent head, and population (dependents plus heads) distributions of a stable population growing at $r=0.03$. Last, figure 4(c) illustrates the results of changing the child-adult population dependency ratio for fixed dependent and head profiles. The resulting profiles reflect common age-specific patterns of migration.

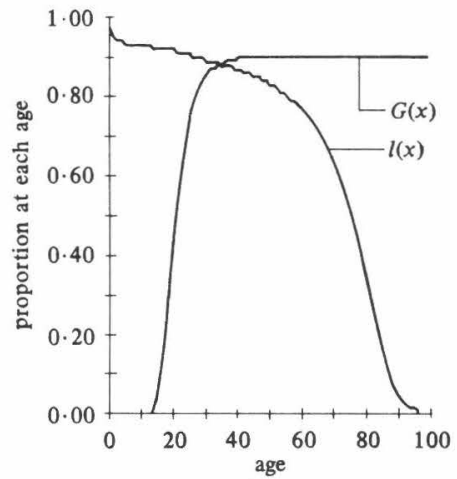

(a) Probability of surviving to age $x[l(x)]$, and proportion of individuals who have ever left home by age $x[G(x)]$.

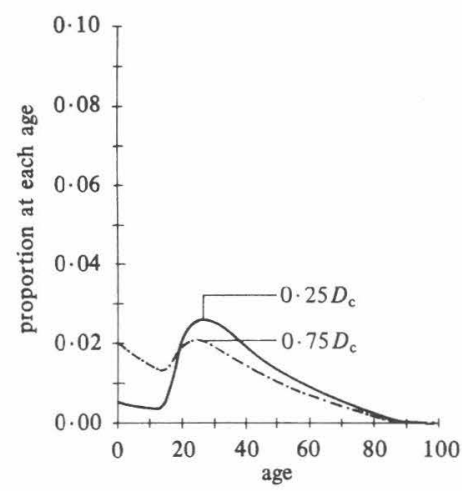

(c) Hypothetical migration profiles obtained from different child-dependency ratios and fixed dependent and head profiles.

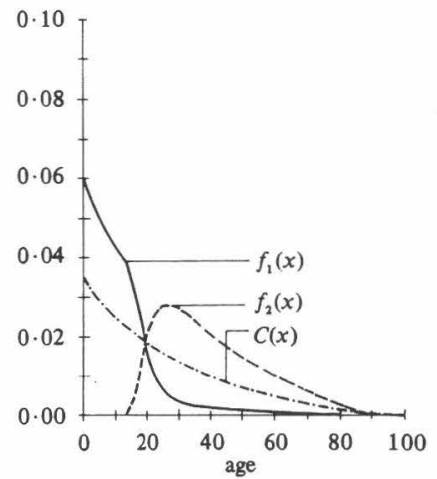

(b) Proportion of dependents at age $x\left[f_{1}(x)\right]$, proportion of heads at age $x\left[f_{2}(x)\right]$, and the resulting age-population distribution $[C(x)]$.

Figure 4. Sequence of age compositions that reflect the influences of changing dependency levels. 
4 Dependency relationships: a two-sex analysis by age of head

The above analysis suggests that more disaggregated age profiles might help to identify the impacts of family dependency on the shapes of age-specific migration schedules. For example, it appears that differences between the age compositions of the population at large and that of the population of migrants may be a consequence of differences in the ratios of the number of dependents per head at each age. And the introduction of individuals of one sex as dependents of another requires further disaggregation. A matrix formulation of family composition relationships may be used to illuminate the interaction of these several dimensions (Akkerman, 1980).

Let ${ }^{y} K_{\mathrm{D}}(x)$ denote the number of dependent individuals at age $x$, whose head is of age $y$, and let $K_{\mathrm{H}}(y)$ denote the number of such heads. Dividing each of the former by the latter defines the dependency coefficient $a_{x y}$. Introducing a left superscript of $k$ or $o$ to distinguish between population-related and migrant-related coefficients, and expressing the set of such coefficients in the form of a matrix gives

$$
\mathbf{A}_{k}=\left[\begin{array}{ccc}
{ }^{k} a_{11} & \ldots & { }^{k} a_{1} \\
\vdots & & \vdots \\
{ }^{k} a_{n 1} & \ldots & { }^{k} a_{n n}
\end{array}\right]=\left[{ }^{k} a_{x y}\right],
$$

where

$$
\begin{array}{ll}
{ }^{k} a_{x y}=\frac{{ }^{y} K_{\mathrm{D}}(x)}{K_{\mathrm{H}}(y)}, & \text { for } y \geqslant y_{0} \\
{ }^{k} a_{x y}=0, & \text { otherwise, }
\end{array}
$$

and $y_{0}$ is the earliest age at which individuals become family heads.

A directly analogous dependency matrix $\mathbf{A}_{0}$ may be defined for the migrant population.

Given the matrix $\mathbf{A}_{k}$ and the number of family heads in the population, at each of several ages and expressed as the vector $K_{\mathrm{H}}$, say, we can obtain the corresponding vector of the dependent population

$$
K_{\mathrm{D}}=\mathrm{A}_{k} K_{\mathrm{H}} \text {, }
$$

Since this vector of dependent population together with the associated vector of family heads defines the total population at each age, we have that

$$
K=\left(\mathbf{I}+\mathbf{A}_{k}\right) K_{\mathrm{H}} \text {. }
$$

The elements of the dependency (population) matrix $\mathbf{A}_{k}$ can be decomposed into level and composition components:

$$
{ }^{k} a_{x y}=\frac{{ }^{y} K_{\mathrm{D}}(x)}{K_{\mathrm{H}}(y)}=\frac{{ }^{y} K_{\mathrm{D}}(\cdot)}{K_{\mathrm{H}}(y)} \frac{{ }^{y} K_{\mathrm{D}}(x)}{{ }^{y} K_{\mathrm{D}}(\cdot)}={ }^{k} u_{y}{ }^{k} d_{x y},
$$

say, where ${ }^{y} K_{\mathrm{D}}(\cdot)$ denotes the total number of dependents whose heads are of age $y$.

Thus the first of the two terms in the product set out in equation (17) refers to level and the second to composition. Collecting the level coefficients to define a diagonal matrix $U_{k}$ and expressing the composition coefficients in the form of a matrix $\mathrm{D}_{k}$, gives the matrix version of equation (17)

$$
\mathbf{A}_{k}=\mathbf{D}_{k} \mathbf{U}_{k} \text {. }
$$

Inserting this decomposition into equation (16) gives

$$
\boldsymbol{K}=\left(\mathbf{I}+\mathbf{D}_{k} \mathrm{U}_{k}\right) K_{\mathrm{H}},
$$


and introducing a disaggregation by sex, we obtain

$$
\left[\begin{array}{l}
{ }_{\mathrm{M}} K \\
{ }_{\mathrm{F}} K
\end{array}\right]=\left[\begin{array}{ll}
\mathrm{I}+{ }_{\mathrm{MM}} \mathrm{D}_{k \mathrm{MM}} \mathrm{U}_{k} & { }_{\mathrm{MF}} \mathrm{D}_{k \mathrm{MF}} \mathrm{U}_{k} \\
{ }_{\mathrm{FM}} \mathrm{D}_{k \mathrm{FM}} \mathrm{U}_{k} & \mathrm{I}+{ }_{\mathrm{FF}} \mathrm{D}_{k \mathrm{FF}} \mathrm{U}_{k}
\end{array}\right]\left[\begin{array}{l}
{ }_{\mathrm{M}} K_{\mathrm{H}} \\
{ }_{\mathrm{F}} K_{\mathrm{H}}
\end{array}\right],
$$

where the two left subscripts on the component matrices indicate the sex of the dependent and the head, respectively. In this way we may calculate, for example, the vector of male dependents in the population as

$$
{ }_{\mathrm{M}} K_{\mathrm{D}}={ }_{\mathrm{MM}} \mathrm{D}_{k \mathrm{MM}} \mathrm{U}_{k \mathrm{M}} K_{\mathrm{H}}+{ }_{\mathrm{MF}} \mathrm{D}_{k \mathrm{MF}} \mathrm{U}_{k \mathrm{~F}} K_{\mathrm{H}},
$$

and that of the male population as

$$
{ }_{\mathrm{M}} K={ }_{\mathrm{M}} K_{\mathrm{H}}+{ }_{\mathrm{M}} K_{\mathrm{D}} \text {. }
$$

The derivation of an analogous set of equations for migrants is straightforward and gives

$$
O=\left(\mathrm{I}+\mathrm{D}_{o} \mathrm{U}_{o}\right) O_{\mathrm{H}},
$$

and

$$
\left[\begin{array}{c}
{ }_{\mathrm{M}} O \\
{ }_{\mathrm{F}} O
\end{array}\right]=\left[\begin{array}{ll}
\mathrm{I}+{ }_{\mathrm{MM}} \mathrm{D}_{O \mathrm{MM}} \mathrm{U}_{o} & \mathrm{MF}_{O \mathrm{MF}} \mathrm{U}_{o} \\
{ }_{\mathrm{FM}} \mathrm{D}_{O \mathrm{FM}} \mathrm{U}_{O} & \mathrm{I}+{ }_{\mathrm{FF}} \mathrm{D}_{O \mathrm{FF}} \mathrm{U}_{O}
\end{array}\right]\left[\begin{array}{c}
{ }_{\mathrm{M}} O_{\mathrm{H}} \\
{ }_{\mathrm{F}} O_{\mathrm{H}}
\end{array}\right],
$$

as the migrant analogs to equations (18) and (19), respectively.

Let $\mathbf{R}$ be a diagonal matrix of head migration rates,

$$
r_{y}=\frac{O_{\mathrm{H}}(y)}{K_{\mathrm{H}}(y)},
$$

then

$$
O_{\mathrm{H}}=\mathrm{R} K_{\mathrm{H}} .
$$

Solving for $K_{\mathrm{H}}$ in equation (18) we obtain

$$
K_{\mathrm{H}}=\left(\mathbf{I}+\mathbf{D}_{k} \mathbf{U}_{k}\right)^{-1} K \text {, }
$$

whence

$$
O=\left(\mathbf{I}+\mathbf{D}_{o} \mathbf{U}_{o}\right) \mathbf{R}\left(\mathbf{I}+\mathbf{D}_{k} \mathbf{U}_{k}\right)^{-1} K .
$$

The principal equations of this section have been set out in table 3 .

Table 3. A summary of the principal matrix equations.

\section{Population}

$K=\left(\mathrm{I}+\mathrm{D}_{k} \mathbf{U}_{k}\right) K_{\mathrm{H}}$

Migrants

$O=\left(\mathrm{I}+\mathrm{D}_{o} \mathrm{U}_{o}\right) O_{\mathrm{H}}$

Migrants/population

$O_{\mathrm{H}}=\mathbf{R} K_{\mathrm{H}}$

$O=\left(\mathbf{I}+\mathbf{D}_{o} \mathrm{U}_{o}\right) \mathbf{R}\left(\mathbf{I}+\mathbf{D}_{k} \mathrm{U}_{k}\right)^{-1} K$

Variables affecting the migration proportion schedule, $N(x)$

the composition coefficients, ${ }^{o} d_{x y}$ and ${ }^{k} d_{x y}$ the level coefficients, ${ }^{o} u_{y}$ and ${ }^{k} u_{y}$ the migration rates of heads, $r_{y}$ 


\section{Sensitivity experiments}

The above matrix formulation of head and dependency relationships in the population and among migrants identifies the contributions of three fundamental components to the migration proportion schedule, $N(x)$ :

1. the composition coefficients, ${ }^{o} d_{x y}$,

2. the level coefficients, ${ }^{\circ} u_{y}$, and

3 . the age distribution of head migrants, $O_{\mathrm{H}}(x)$.

Their interaction is defined by equation (23), which establishes, for example, that the vector of age-specific male migrants may be expressed as the sum of: the vector of male head migrants, the vector of male dependent migrants traveling with male head migrants, and the vector of male dependent migrants moving with female head migrants:

$$
{ }_{\mathrm{M}} O={ }_{\mathrm{M}} O_{\mathrm{H}}+{ }_{\mathrm{MM}} \mathrm{D}_{o \mathrm{MM}} \mathrm{U}_{O \mathrm{M}} O_{\mathrm{H}}+{ }_{\mathrm{MF}} \mathrm{D}_{O \mathrm{MF}} \mathrm{U}_{o \mathrm{~F}} O_{\mathrm{H}},
$$

or

$$
{ }_{\mathrm{M}} O={ }_{\mathrm{M}} O_{\mathrm{H}}+{ }_{\mathrm{M}} O_{\mathrm{D}} \text {. }
$$

Equations (20) and (21) express the corresponding relationships in the population at large.

Figures 5 and 6 illustrate the matrices of composition coefficients for our Mexican data. Figure 5 refers to the migrant-related matrices ${ }_{\mathrm{MM}} \mathrm{D}_{o},{ }_{\mathrm{MF}} \mathrm{D}_{o},{ }_{\mathrm{FM}} \mathrm{D}_{o}$, and ${ }_{\mathrm{FF}} \mathrm{D}_{o}$. Figure 6 presents the corresponding population-related matrices ${ }_{\mathrm{MM}} \mathrm{D}_{k},{ }_{\mathrm{MF}} \mathrm{D}_{k},{ }_{\mathrm{FM}} \mathrm{D}_{k}$, and ${ }_{F F} D_{k}$. (Recall that the area under each curve is set equal to unity for ease of comparison.)
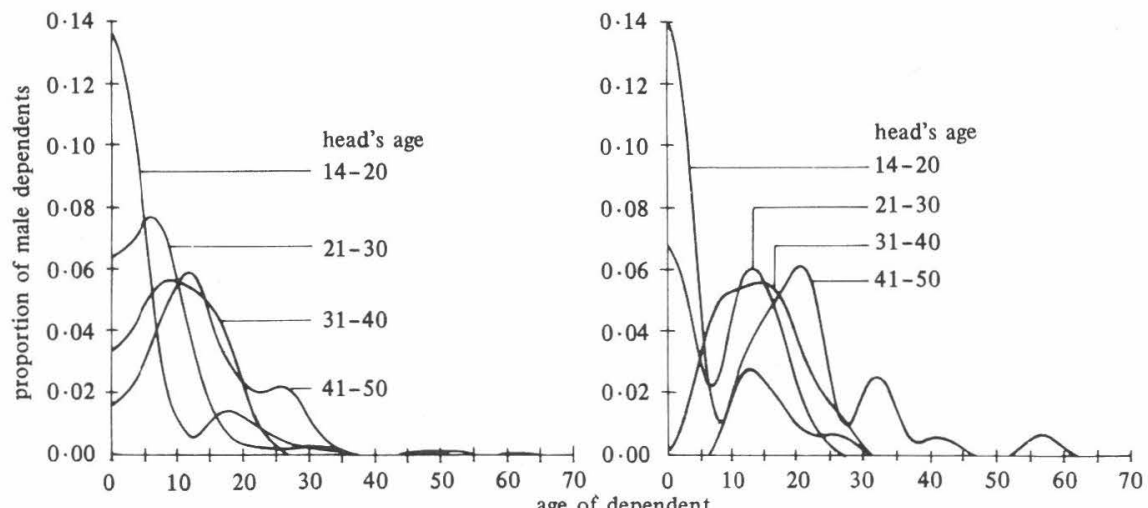

Male dependents with male heads, MM $D_{0}$

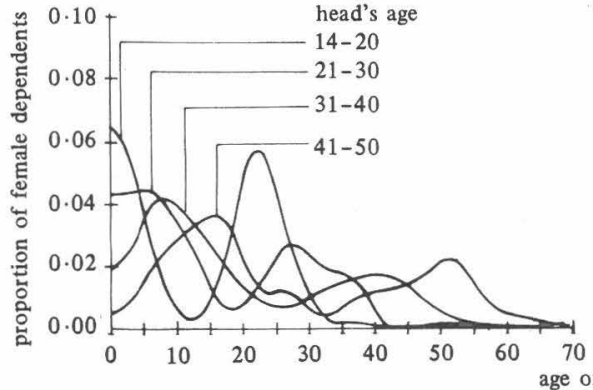

Male dependents with female heads, ${ }_{\text {MF }} \boldsymbol{D}_{o}$

Female dependents with male heads, ${ }_{F F} D_{o}$

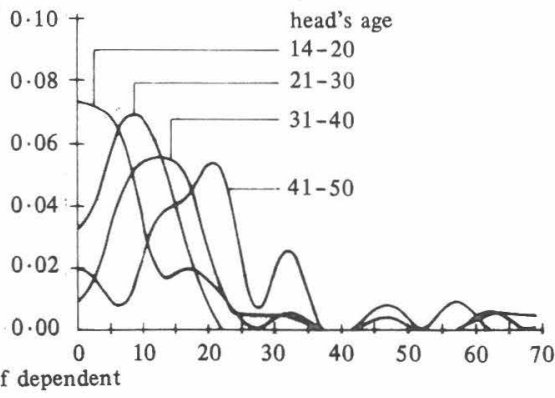

Female dependents with female heads, ${ }_{\mathrm{FF}} \boldsymbol{D}_{o}$

Figure 5. Age-specific migration distribution of male and female dependents by age and sex of head: Mexico, 1970. 
Each age profile in figures 5 and 6 describes a row of the particular D matrix. It apportions the total number of dependents to different ages or age groups. These dependents are generated by multiplying the number of heads at each age by the appropriate dependency level coefficient in the $\mathbf{U}$ matrix. The diagonal elements of the latter matrix in the Mexican data are illustrated in figure 7, which presents the diagonal elements of the matrices ${ }_{\mathrm{MM}} \mathrm{U}_{o},{ }_{\mathrm{MM}} \mathrm{U}_{k},{ }_{\mathrm{MF}} \mathrm{U}_{o},{ }_{\mathrm{MF}} \mathrm{U}_{k},{ }_{\mathrm{FM}} \mathrm{U}_{o},{ }_{\mathrm{FM}} \mathrm{U}_{k}, \mathrm{FF}_{\mathrm{FF}} \mathrm{U}_{o}$, and ${ }_{\mathrm{FF}} \mathrm{U}_{k}$.

Finally, the age compositions of the various $O$ and $K$ vectors have already appeared in the form of $N$ and $C$ vectors, in figures 1 and 2 .

With one exception, the age profiles of the composition coefficients set out in figures 5 and 6 , exhibit patterns that are broadly similar: starting with an approximately negative exponential curve for the youngest age group of heads, the profiles assume bell-shaped curves that move along the horizontal axis for all subsequent age groups. The one exception is the behavior of the age profile of female dependents traveling with male heads. Here the curve is bimodal, with the two peaks representing the ages of daughters and wives, respectively. As with the other profiles, however, older heads are associated with older dependency profiles: the curves move to the right on the age axis for the older age groups of heads.

In general, the migrant-related age profiles illustrated in figure 5 do not differ significantly from the corresponding population-related profiles set out in figure 6 . The minor differences appear to be more a consequence of small sample sizes than of fundamental differences in patterns of behavior. Since data on family composition
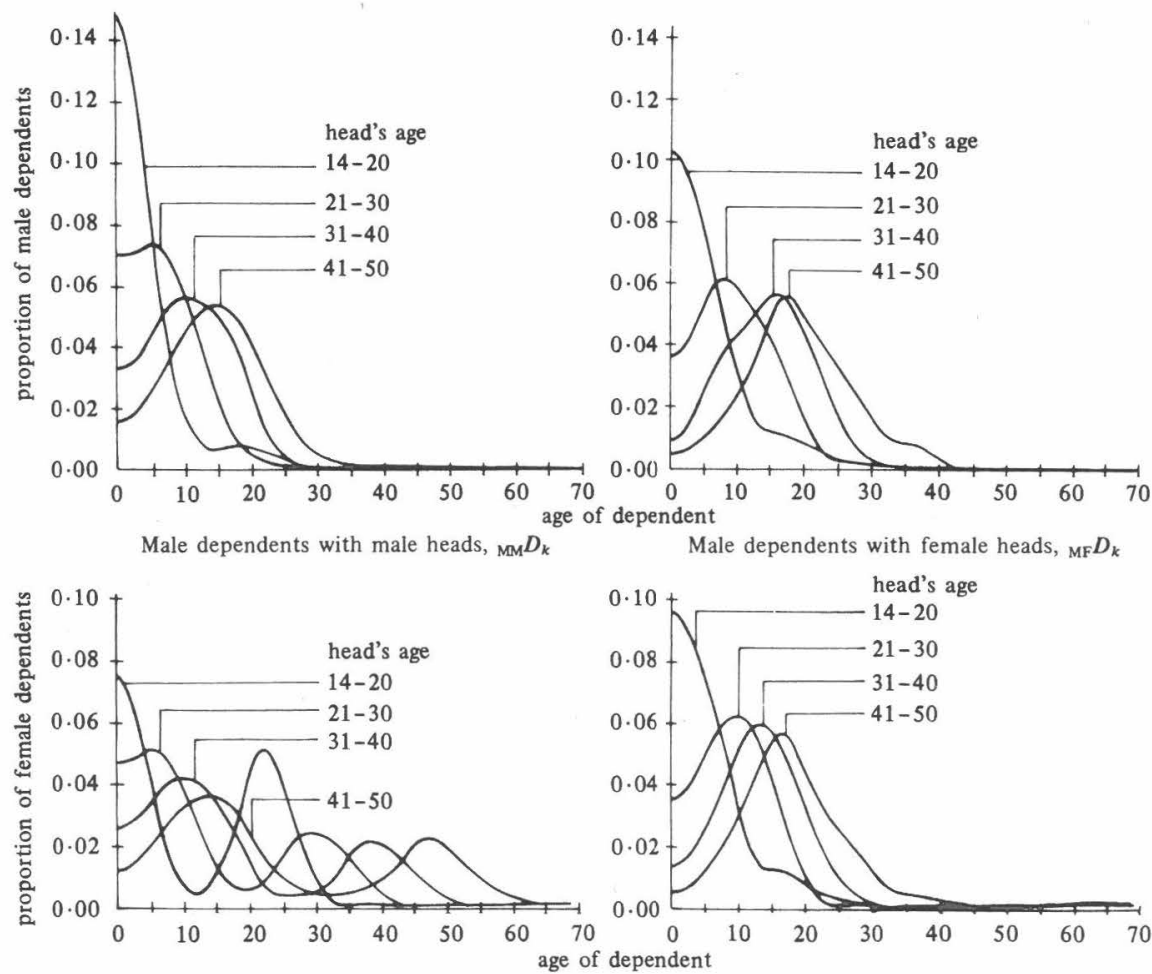

Male dependents with female heads, ${ }_{\text {MF }} D_{k}$

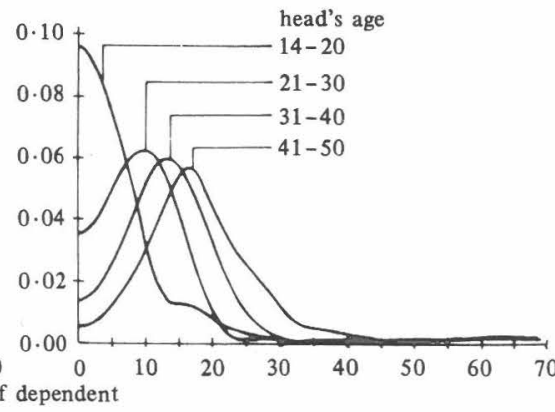

Female dependents with male heads, FM $D_{k}$

Female dependents with female heads, ${ }_{\mathrm{FF}} \boldsymbol{D}_{k}$

Figure 6. Age-specific population distribution of male and female dependents by age and sex of head: Mexico, 1970. 

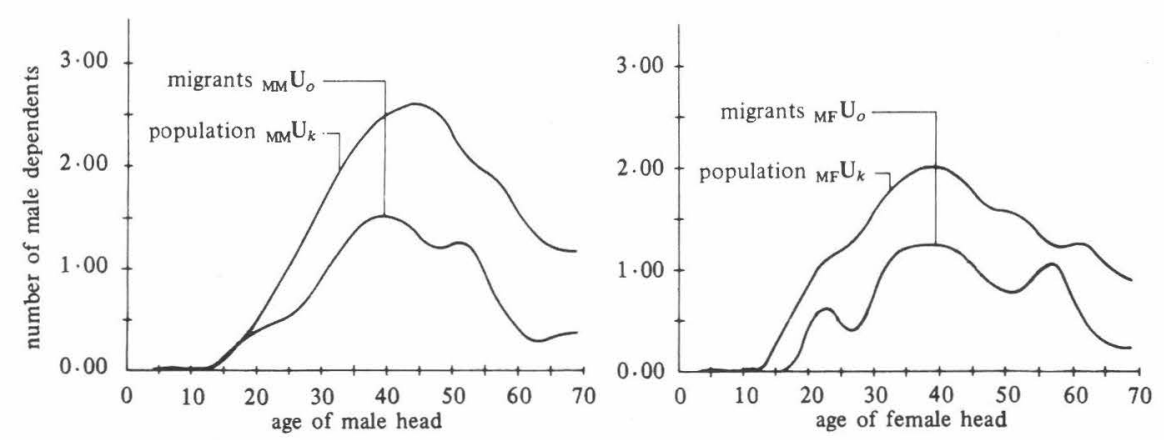

Male dependent-male head

Male dependent-female head
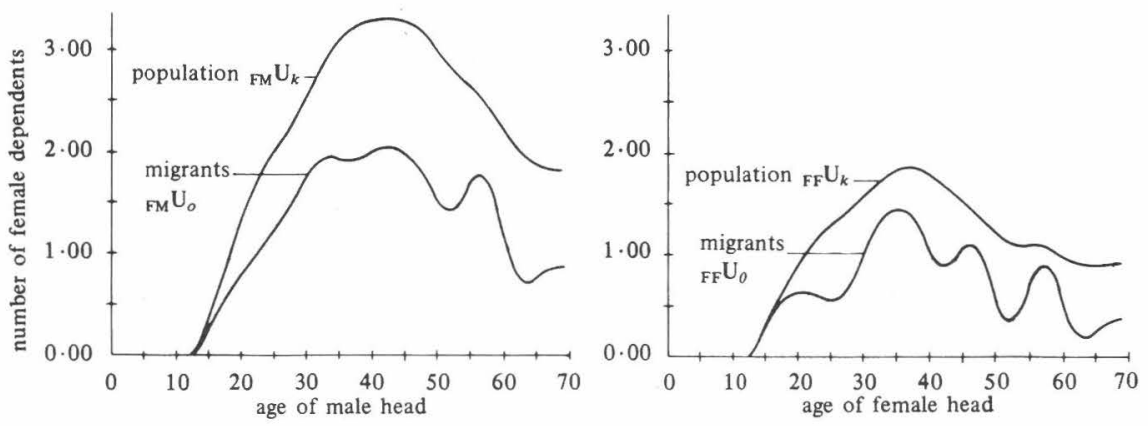

Female dependent-male head

Female dependent-female head

Figure 7. Dependency level profiles for population and migrants: Mexico, 1970.

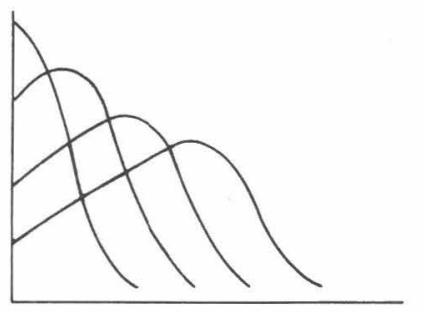

Common age compositions of dependents traveling with heads of different ages: D

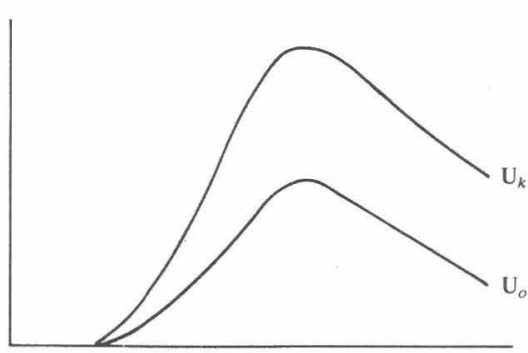

Dependency levels by age of head

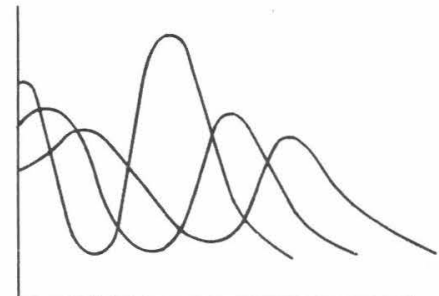

Age composition of female dependents traveling with male heads: $F M D$

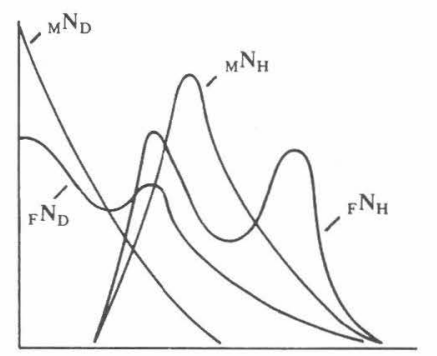

Migration proportions: heads and dependents

Figure 8. Model age profiles of dependency compositions and levels of migration proportions of heads and dependents. 
are generally more readily available for the population at large than for migrants, this similarity could have important implications.

What may be true for age profiles is apparently not true of levels. Figure 7 shows that the number of dependents per head is lower at all ages for the population of migrants than for the population at large, that is, ${ }^{o} u_{y}<{ }^{k} u_{y}$. For both, however, the unimodal curve rises from the youngest headship age to a peak in the late thirties or early forties, with the peak for migrants possibly occurring at a slightly younger age. The highest levels are exhibited by female dependents traveling with male heads.

The minor variations and irregularities in the patterns exhibited in figures 5, 6, and 7 obscure the broad underlying age profiles that are indicated by the data. These underlying age profiles, illustrated in figure 8 , are in a sense 'model' profiles. They reflect visually some of the observations made in the above paragraphs.

Expressing an age-specific vector of migrants as a function of the $\mathbf{D}$ and $\mathbf{U}$ matrices and the $O$ vector, as in equation (26), allows us to carry out a few sensitivity experiments to better understand their influence on the behavior of the associated migration proportion schedule $N$. Figures 9,10 , and 11 present the impacts on the latter of changes in each of the three former components.

Figure 9 shows the impact of substituting population-related dependency age compositions in place of their migrant-related counterparts. Specifically, the $\mathbf{D}_{o}$ matrix is replaced by the corresponding $\mathbf{D}_{k}$ matrix. The impact of this substitution is insignificant in the male proportion schedules and minor in the female profiles. In the latter the principal effect is a moderate increase in the relative share of the $0-4$ year olds and a compensating decline among 20-24 year olds.
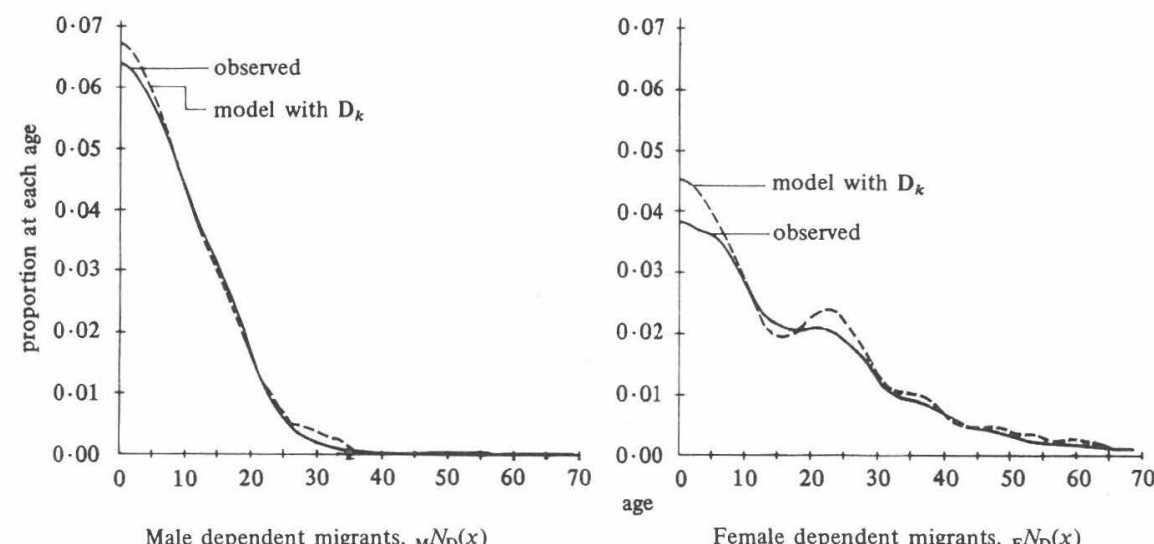

Male dependent migrants, ${ }_{\mathrm{M}} N_{\mathrm{D}}(x)$

Female dependent migrants, ${ }_{\mathrm{F}} N_{\mathrm{D}}(x)$
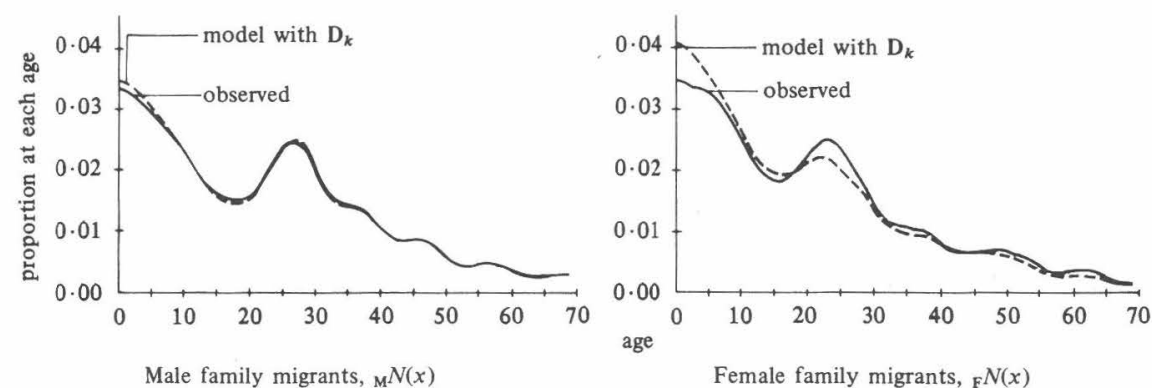

Male family migrants, ${ }_{\mathrm{M}} N(x)$

Female family migrants, ${ }_{\mathrm{F}} N(x)$

Figure 9. Observed and model (with $\mathbf{D}_{k}$ ) age-specific migration distribution of dependents and family migrants by sex. 
Although changes in dependency age compositions produce only minor impacts on the migration proportion schedule, changes in dependency levels have dramatic effects in the case of male migrants ${ }^{(4)}$. Figure 10 shows that decreasing the level matrix $\mathbf{U}_{o}$ by a half increases the labor-dominance of the male migration age profile, whereas increasing $\mathbf{U}_{o}$ to the level of the population at large shapes the curve in the opposite direction. Apparently high dependency levels give the $N(x)$ schedule a distinctive child-dependency shape and thereby sharply differentiate the migration proportion schedules of developing countries such as Mexico from those of developed nations.

For the final sensitivity experiment, we show in figure 11 the effects of replacing the $O$ vectors by their $K$ vector counterparts. The impacts of this on the dependent migrant profiles are minimal; however, the same cannot be said for the aggregation of heads and dependents. There the principal impact is to increase the share of the pre-labor force age groups past the age of five years at the expense of infant and 20-30-year-old migrants. The $N(x)$ schedule tends toward the shape of the $C(x)$ age profile.

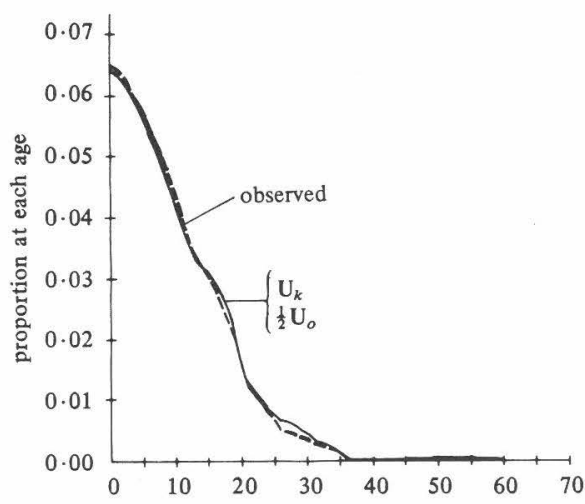

Male dependent migrants, ${ }_{\mathrm{M}} N_{\mathrm{D}}(x)$
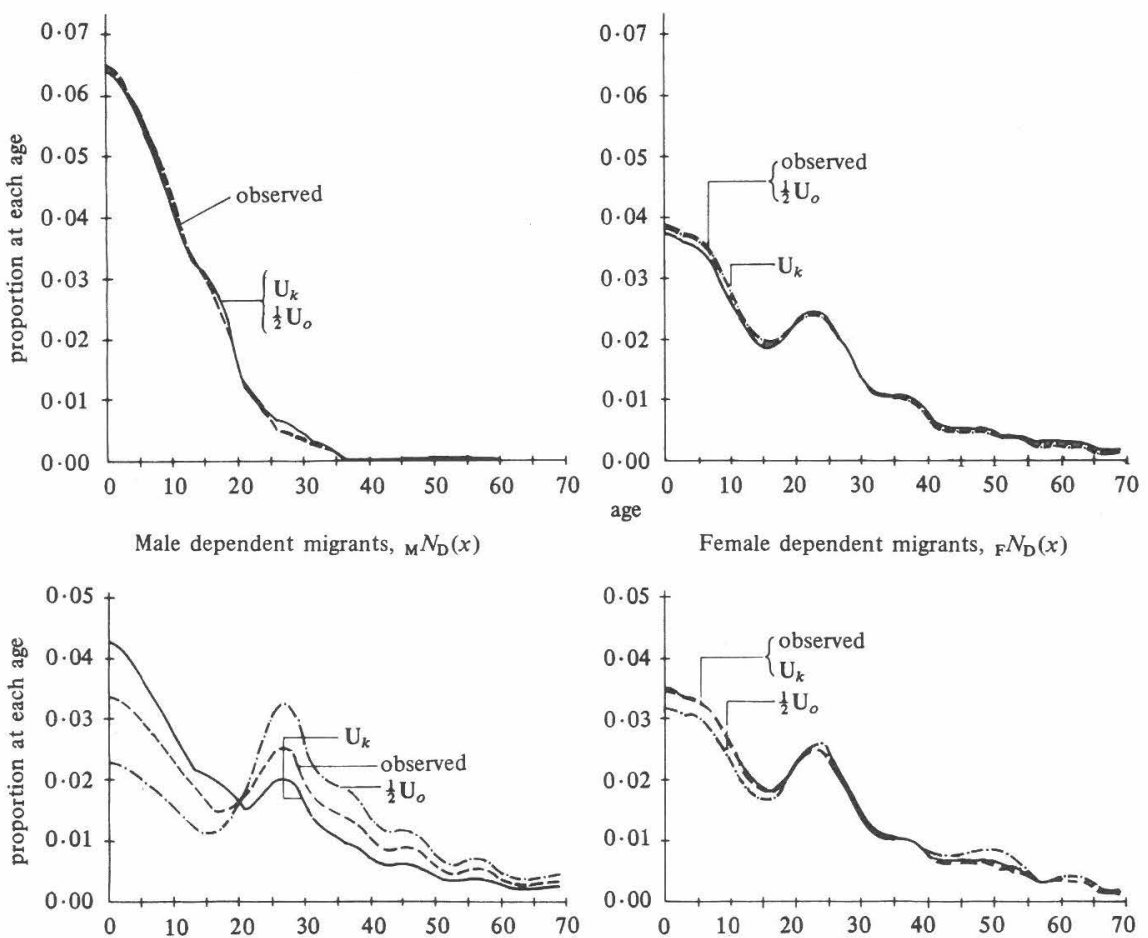

Male family migrants, ${ }_{\mathrm{M}} N(x)$

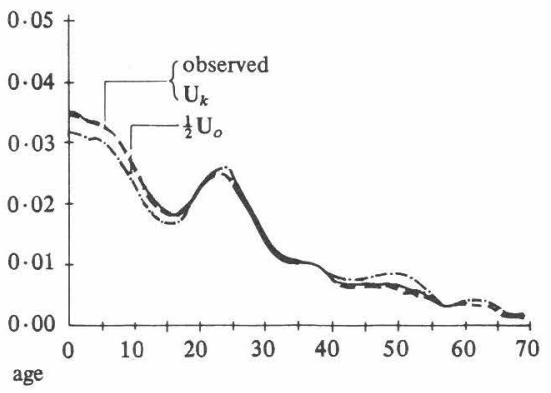

Female family migrants, $\mathrm{F} N(x)$

Figure 10. Observed and model (with $\mathbf{U}_{k}$ or $\frac{1}{2} \mathrm{U}_{o}$ ) age-specific migration distributions of dependents and family migrants by sex.

(4) Curiously, the same impact is not manifested by the female schedule. The reason for this is not readily apparent, although it seems likely that the bimodal shape of the dependency age profile distributes the impacts of changes in the $\mathbf{U}$ matrix more uniformly across all ages. 

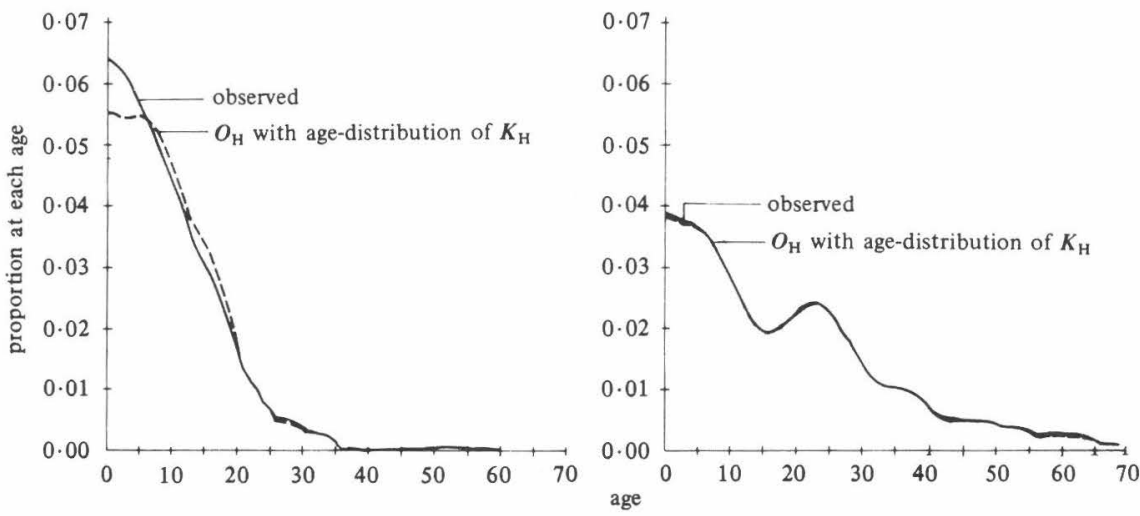

Male dependent migrants, ${ }_{\mathrm{M}} N_{\mathrm{D}}(x)$

Female dependent migrants, ${ }_{\mathrm{F}} N_{\mathrm{D}}(x)$
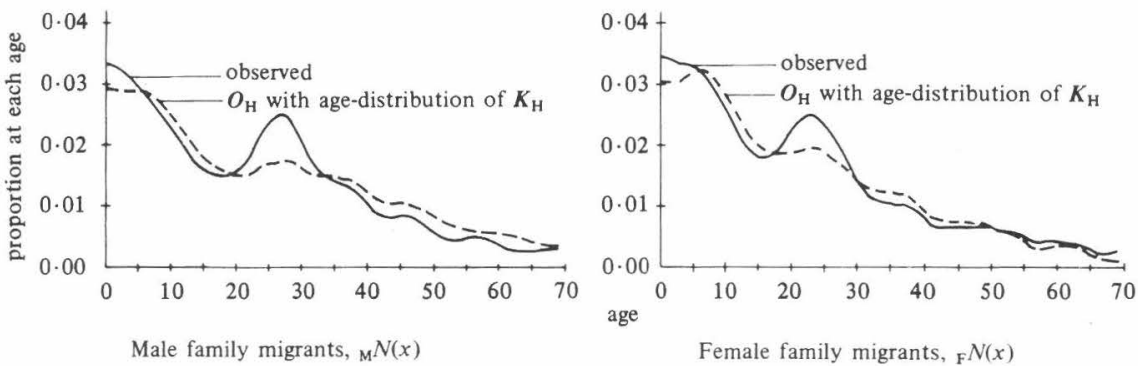

Male family migrants, ${ }_{\mathrm{M}} N(x)$

Female family migrants, ${ }_{\mathrm{F}} N(x)$

Figure 11. Observed and model (with age-distribution of $K_{\mathrm{H}}$ ) age-specific migration distributions of dependents and family migrants by sex.

\section{Conclusion}

The age composition of a population reflects the recent history of fertility and mortality to which the population has been exposed. For example, high rates of natural increase give rise to population age compositions that taper more rapidly with age, and zero growth rates ultimately produce age compositions that are nearly rectangular until ages 50 or 60 , tapering rapidly thereafter as death rates increase among the aged. Thus one may conclude that the age composition of a population tells us something about patterns of fertility and mortality. What does the age composition of migrants tell us?

If migration is generally undertaken by families as a unit, the age composition of migrants tells us something about family patterns. The aim of this paper has been to identify some of the effects of family dependency on sex-specific migration proportion schedules. Toward this end we have introduced a decomposition of migration flows into independent and dependent flows, with the latter expressed as a function of dependency age compositions and levels, disaggregated by age and sex of family head. Sensitivity experiments carried out by varying the values taken on by the principal components of such a decomposition indicate that, at least for the Mexican data, the shape of the migration proportion schedule $N(x)$ is mostly sensitive to changes in the dependency levels and in the age distribution of family heads.

To make more transparent the influence that dependency relationships have on the age composition of migrant streams, model migration proportion schedules were adopted in the single-sex analysis. Extending this approach to the two-sex analysis, however, is beyond the scope of this paper and will be carried out in future research. 
Other profitable directions for further research could emerge from a closer integration of this analysis with the classical sociological literature on the demography of the family. For example, it was pointed out in section 1 that the age-specific profiles of male dependents are steeper than those of females and that this may be a function of the age at which children leave the family home. If the dependency compositions of migrants are related to early or late stages of leaving home, then figure 12(a) suggests schematically how this influence may be manifested. Figure 12(b) traces the same impacts on the migration proportion schedules $N(x)$.

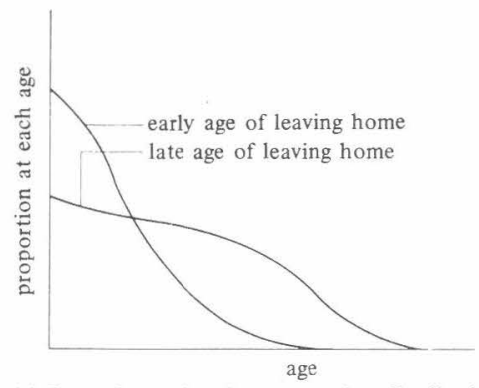

(a) Dependent migration proportion distributions

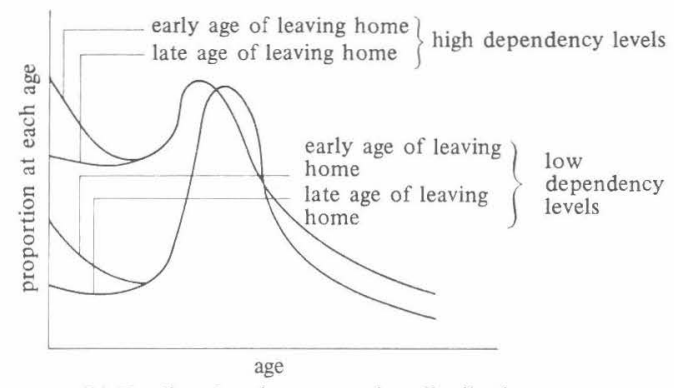

(b) Family migration proportion distributions

Figure 12. Hypothetical dependent and family migration proportion distributions according to ages of leaving home and dependency levels.

The event of leaving the home usually cannot be divorced from the reason or cause for migrating:

"For sons, the most common destination when leaving home for marriage was another suburb, or the same suburb. If the reason was independence, the son would most likely move to another suburb; if the reason was travel, he would most likely go overseas; if the reason was job or education, he probably would go elsewhere in the same state, or interstate. A similar pattern emerges for daughters, except that those leaving for a job would be more likely to move to another suburb or elsewhere in the same state, and those leaving for education were likely to move only as far as another suburb" (Young, 1977, page 205).

Thus, the study of the age profiles of migrants, both for heads and for dependents, may usefully draw on the insights of family demography and the role of the family life cycle to explain variations in patterns exhibited by migration proportion schedules in societies at different stages of development.

Acknowledgements. The authors are grateful to the Center for Latin American Demography of the United Nations, Santiago, Chile and to the Division of Statistics, Ministry of Budget and Programming of the Republic of Mexico for providing the Mexican data used in this paper.

\section{References}

Akkerman A, 1980 "On the relationship between household composition and population age distribution" Population Studies 34 (3) 525-534

Brass W, 1971 "On the scale of mortality" in Biological Aspects of Demography Ed. W Brass (Taylor and Francis, London) pp 69-110

Castro L J, Rogers A, 1981 "Model migration schedules: a simplified formulation and an alternative parameter estimation method" WP-81-63, International Institute for Applied Systems Analysis, Laxenburg, Austria

Coale A J, McNeil D R, 1972 "The distribution by age of the frequency of first marriage in a female cohort" Journal of the American Statistical Association 67743 -749

FSO, 1970 IX Censo General de Poblacion Federal Statistical Office, Mexico City, Mexico

Kobrin F E, 1976 "The fall in household size and the rise of the primary individual in the United States" Demography 13 (1) 127-138 
Kuznets S, 1978 "Size and age structure of family households: explanatory comparisons" Population and Development Review 4 (2) 187-223

Long L, 1974 "Women's labor force participation and the residential mobility of families" Social Forces 52 (March) $342-347$

Rodriguez G, Trussell J, 1980 "Maximum likelihood estimation of the parameters of Coale's model nuptiality schedule from survey data" Technical Bulletin 7 Tech 1261, World Fertility Survey, International Statistical Institute, Voorburg, Netherlands

Rogers A, Castro L J, 1981 "Model migration schedules" RR-81-30, International Institute for Applied Systems Analysis, Laxenburg, Austria

Ryder N B, 1978 "Methods in measuring the family life cycle" in Proceedings, International Population Conference, Mexico, 1977 International Union for the Scientific Study of Population, Liège, Belgium, pp 219-226

UN, 1973 Manual VII: Methods of Projecting Households and Families (United Nations, New York) Young C, 1977 The Family Life Cycle, Australian Family Formation Project monograph 6 , Department of Demography, Australian National University, Canberra, Australia 


\section{RELATED PUBLICATIONS ON AGE PROFILES OF MIGRATION}

1. Andrei Rogers, Richard Raquillet, and Luis Castro, Model migration schedules and their applications. Environment and Planning A, 10(5):475-502.

2. Andrei Rogers and Luis Castro, Age patterns of migration: cause-specific profiles. IIASA Reports, 4(1):125-159.

3. Andrei Rogers and Luis Castro, Model Migration Schedules. RR-81-30.

4. Luis Castro and Andrei Rogers, Model Migration Schedules: A Simplified Formulation and an Alternative Parameter Estimation Method. WP-81-63.

5. Andrei Rogers and Luis Castro, Model schedules in multistate demographic analysis: the case of migration. Pages 113-154 in Multidimensional Mathematical Demography, K.C. Land and A. Rogers, editors. New York: Academic Press.

6. Luis Castro and Andrei Rogers, What tile Age Composition of Migrants Can Tell Us. WP-82-94. 
